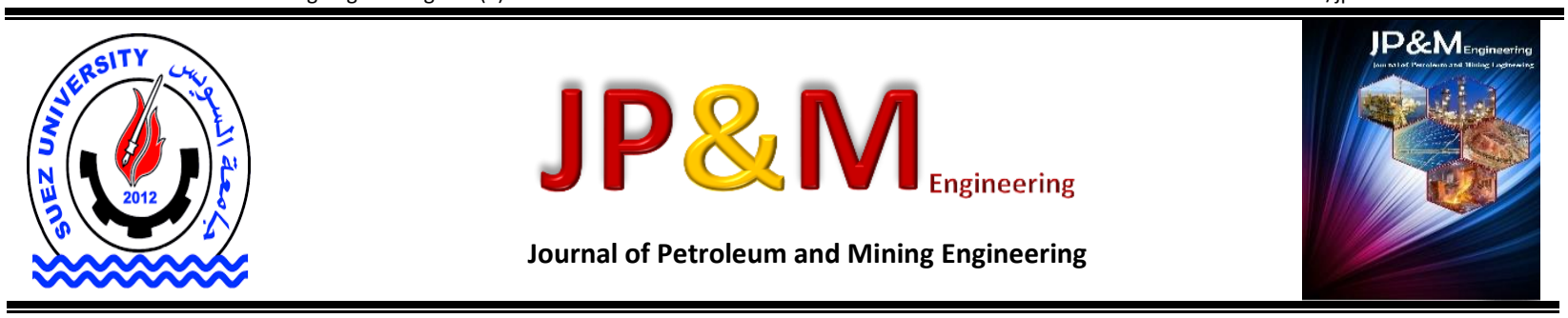

\title{
Fabrication of Aluminum Matrix Nanocomposites by Hot Compaction
}

\author{
Yehia, H. M. ${ }^{1 *}$, Menisy, M. ${ }^{2}$, Allama, S. ${ }^{1}$, Kaytbay, S. $^{3}$ \\ ${ }^{1}$ Faculty of Industrial Education, Helwan University, Cairo, Egypt \\ ${ }^{2}$ Egypt Railways, Cairo, Egypt \\ ${ }^{3}$ Mechanical Engineering Department, Benha Faculty of Engineering, Benha University, Egypt \\ *Corresponding author : hossamelkeber@techedu.helwan.edu.eg, Tel. 02201008087742
}

Article Info.

Received 1 Jul. 2019

Revised 2 Mar. 2020

Accepted 4 Mar. 2020

\section{Keywords}

Aluminum matrix

;Microstructure; Hardness;

Coefficient of Thermal

Expansion.

\begin{abstract}
In this investigation, five aluminum matrix nanocomposites were obtained by the hot pressing at $800 \mathrm{MPa}$ and $600 \mathrm{oC}$. The electrolysis coating technique was utilized to prepare the nano-nickel powder. The fabricated nanocomposites were characterized by studying their chemical composition, microstructure, hardness, and thermal expansion coefficient. The scanning electron microscope of the microstructure of the electroless nickel powder shows that the Ni particles have nano-size where it was less than $100 \mathrm{~nm}$. The EDAX analysis of the fabricated composite that contains 25 wt. \% (Al2O3) in different regions was established. No elements rather than $\mathrm{Al}, \mathrm{Cu}, \mathrm{Ni}$, and $\mathrm{O}$ were observed. The hardness of the aluminum matrix increases as the content of the $\mathrm{Al} 2 \mathrm{O} 3$ increases. In addition, the thermal expansion coefficient was reduced by increasing the Al2O3 content for reasons related to the low thermal expansion of the alumina reinforcement $7.2 \times 10-6 \mathrm{~mm} /{ }^{\circ} \mathrm{C}$ compared with aluminum that has $23.1 \times 10-6 \mathrm{~mm} /{ }^{\circ} \mathrm{C}$.
\end{abstract}

\section{Introduction}

A composite material is a combination of two or more elements insoluble in each other. It can be fabricated by casting, or by extrusion, or by powder metallurgy techniques. Composite materials consistes of a matrix and renforcement. Based on the matrix of the composite, it can be classified into three types that are metal matrix composite (MMC), polymer matrix composite (PMC), ceramic matrix composite (CMC). renforcements are used according to the needs application to achive the required propeties [1-3].

To add the reinforcement to the matrix and distributed it in a good manner without any agglomerations, the powder metallurgy technique is considered a good choice to achieve that. It is also a cost-effective method for producing complex-shaped parts. In this process no need for melting the materials to produce the product where the production process proceeded at a temperature less than the melting temperature of the constituents that make the elements keeping its properties without any changes [4$7,16]$.

In hot consildadion technique temperature and pressure are applied respectivley to sinter a metal matrix. This process is performed to get a product with no porosity. When used for producing a diamond reinforced metal matrix to avoid the graphitization of diamond particles, it presents the advantage to strictly control the processing parameters (temperature, pressure and time). It seems like a spark plasma sintering process, but this process established without 
power, where no need for current to pass it between two electrodes [8-11].

The automobile piston is exposed to severe working conditions from high heat and high impact forces as a result of gas exposure so that it needs to be manufactured from materials that have enormous strength and heat resistance properties. also, it is required to be lightweight and rigid to minimize energy consumption. [12].

Because of the lightweight of the aluminum metal, it was the preferred choice for fabricating the automobile piston. The aluminum metal suffers from its low wear rate and low strength so that it needs to reinforced with a suitable material to improve its properties like alumina, silicon carbide, and or titanium carbide. Not only the morphology and properties of the reinforcement that affect the properties of the matrix, but also the bonding between the constituents has a great effect [13-15].

Rahimian et al. [17, 18] have studied the effect of alumina particle size and concentration on the properties of the aluminum matrix at different sintering temperature and sintering time by the powder metallurgy method. The results illustrate that using finer alumina particles and sintering temperature of $600 \mathrm{oC}$ attributed to producing composites with high relative density (96.5 to $99 \%$ ) and enhanced the mechanical properties.

This experimental investigation aims at explore the impact of the $\mathrm{Al}_{2} \mathrm{O}_{3}$ content on the microstructure, density, thermal expansion, and hardness of the aluminum matrix.

\section{Materials and Methods}

Aluminum powder $99.8 \%$ purity, copper powder of $99.8 \%$ purity, electro-less deposited $\mathrm{Ni}$, and the $\mathrm{Al}_{2} \mathrm{O}_{3}$ of the particle size $5-10 \mu \mathrm{m}$ (Lobo Chemie) are used as raw materials.

The alumina $\mathrm{Al}_{2} \mathrm{O}_{3}$ power is cleaned and coated with 5 wt. \% of Ag from a chemical composition contains $2 \mathrm{~g} / \mathrm{l}$ $\mathrm{AgNO}_{3}, 400 \mathrm{ml} / \mathrm{l}$ formaldehyde, $\mathrm{pH}=11$, and $33 \%$ ammonia solution [5].

The deposition of the nano-nickel metal powder chemical composition is shown it table 1 [2].

Table 1 Chemical composition bath of the electro-less nickel deposition.

\begin{tabular}{|l|l|}
\hline Chemical & g/l \\
\hline $\mathrm{NiCl}_{2}, 6 \mathrm{H}_{2} \mathrm{O}$ & $100(\mathrm{~g} / \mathrm{L})$ \\
\hline $\mathrm{KNaC}_{4} \mathrm{H}_{4} \mathrm{O}_{6} \cdot 4 \mathrm{H}_{2} \mathrm{O}$ & $80(\mathrm{~g} / \mathrm{L})$ \\
\hline $\mathrm{NH}_{4} \mathrm{Cl}$ & $50(\mathrm{~g} / \mathrm{L})$ \\
$\mathrm{pH}$ & 11 \\
$\mathrm{NaPO}$ & $\mathrm{H}_{2}$ \\
Heat & $90(\mathrm{~g} / \mathrm{l})$ \\
\hline
\end{tabular}

The consolidation process is performed by hot pressing at $800 \mathrm{MPa}$ and at $630^{\circ} \mathrm{C}$. Figure 1 shows the heating cycle.

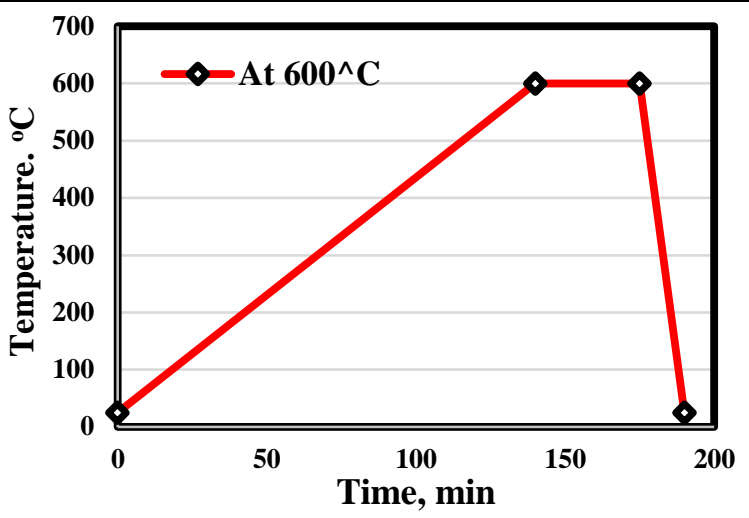

Figure 1 Heating cycle

In order to characterize the microstructure of the fabricated composites, their surfaces are prepared by the grinding, and polishing processes. the scanning electron microscopy (SEM) QUANTA FEG250-EDAX is used to evaluate the microstructure. Also, the EDAX analysis and mapping are performed for the consolidated composites.

The thermal strain is measured according to the experimentally step-up shown in figure 2 , at a temperature ranged from 150 to $450{ }^{\circ} \mathrm{C}$. the thermal strain is determined from the following equation.

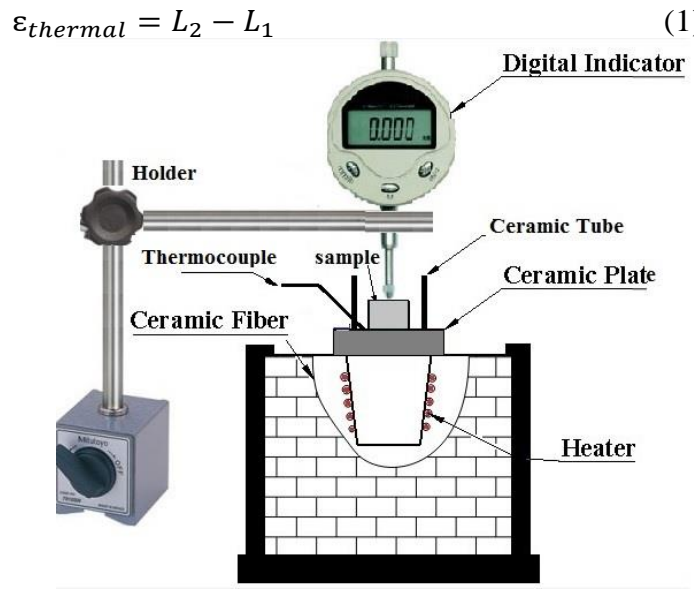

Figure 2 Schematic diagram of thermal strain measurements [6]

The composites macro-hardness is measured using the Vickers hardness tester of the model 5030 SKV England, at $5 \mathrm{~kg}_{\mathrm{f}}$ load and $15 \mathrm{sec}$ holding time.

\section{Results}

Figure 3 shows the morphology of the used raw material powders. It is shown that the raw $\mathrm{Al}_{2} \mathrm{O}_{3}$ powder is irregular with $1-5 \mu \mathrm{m}$ particle size. The raw $\mathrm{Al}, \mathrm{Cu}$, and nano-nickel Ni are nearly spherical. 


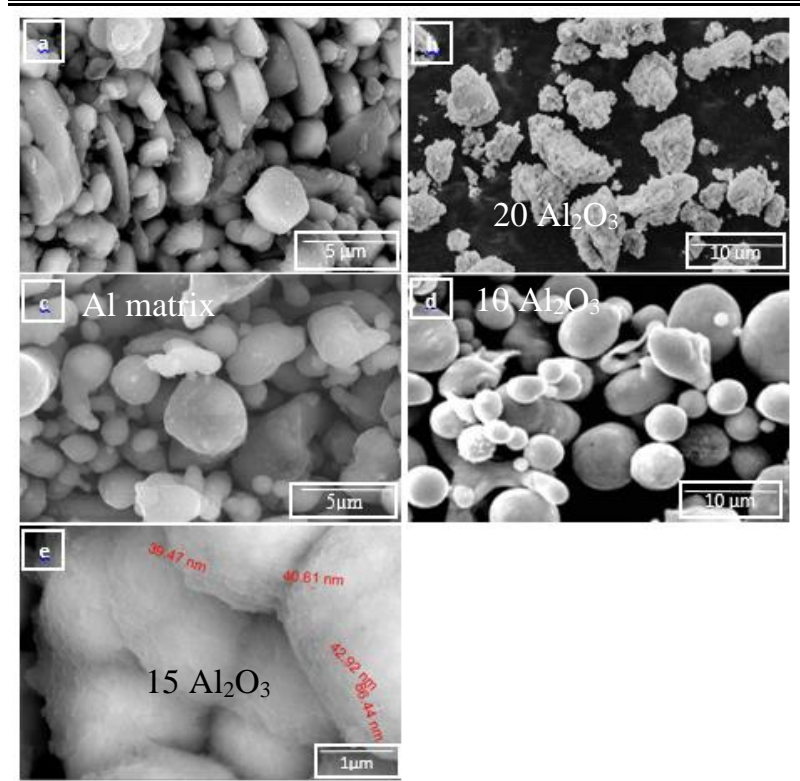

Figure 3 SEM micrograph of the used powders.

\section{Microstructure of Fabricated Composites}

The microstructures of the fabricated composites reinforced with $0,10,15,20$, and 25 wt. \% Al2O3, are shown in figure 4. As shown in the figure the reinforcements, which are $\mathrm{Cu}, \mathrm{Ni}$, and $\mathrm{Al2O} 3$, are homogeneously distributed in the Al matrix. Good adhesion between the different elements of the composite is observed. The main reason for improving the contact between the ceramic $\mathrm{Al} 2 \mathrm{O} 3$ and the $\mathrm{Al}$ matrix may be attributed to the coating of Al2O3 with nano-particles layer of $\mathrm{Ag}$ [4-7].

The EDAX analysis of the fabricated composite sample that contains $25 \mathrm{wt}$. \% (Al2O3-3Ag), is shown in figure 5 . The analysis is performed in different regions to detect the type of the different elements and any new phases. No elements rather than $\mathrm{Al}, \mathrm{Cu}, \mathrm{Ni}$, and $\mathrm{O}$ were observed.

\section{Hardness Evaluation}

Figure 6 illustrates the effect of the (Al2O3-3Ag) on the hardness of the aluminum matrix. the figure shows that the hardness of $\mathrm{Al} / 10 \mathrm{Ni} / 10 \mathrm{Cu}$ increases with increasing the weight percent of the (Al2O3-3Ag). the highest value for the hardness is achived at $25 \mathrm{wt}$. (Al2O3-3Ag). G. Abouelmagd [20] studied the effect of Al2O3 additions and the hot deformation by the extrusion on the hardness and compressive strength of the pure aluminum and showed that the hardness was increased as the percentage of the $\mathrm{Al} 2 \mathrm{O} 3$ increases.

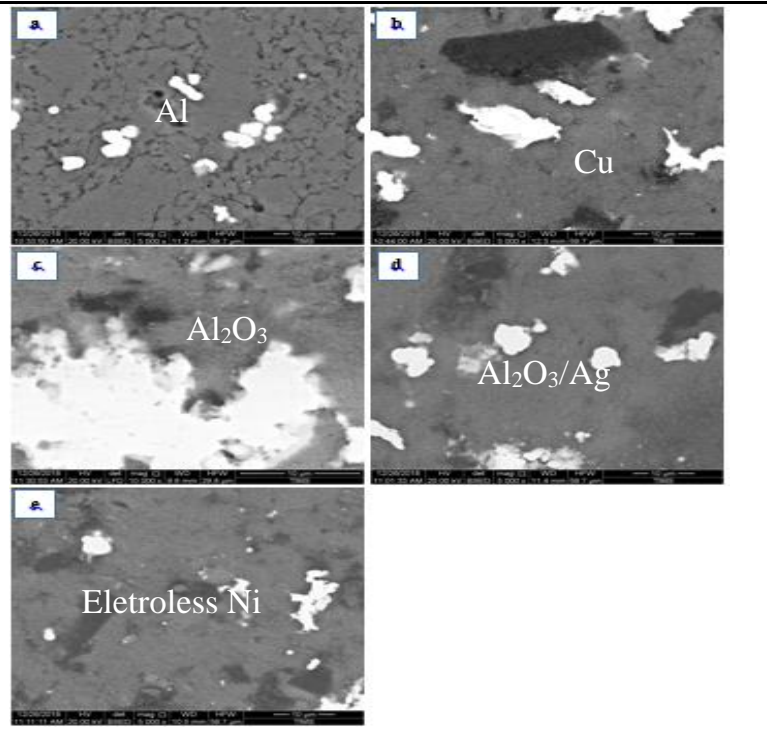

Figure 4 SEM of fabricated Al matrix non- composite
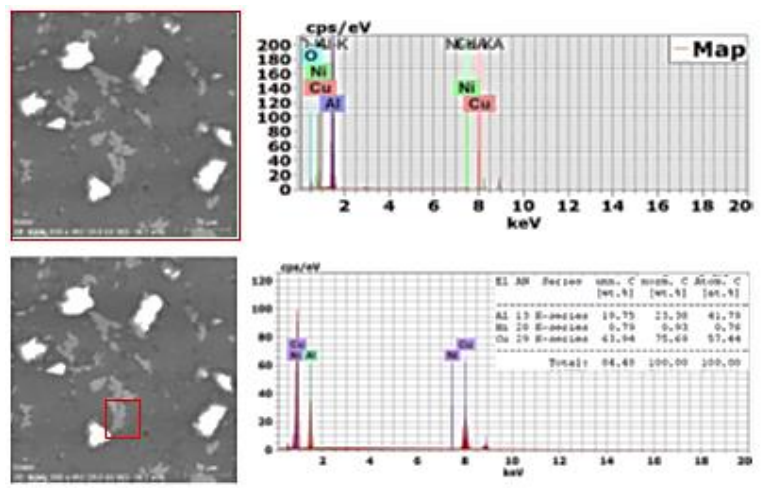

Figure 5 EDAX analysis of the fabricated $\mathrm{Al} / 10 \mathrm{Ni} / 10 \mathrm{Cu} / 25 \mathrm{wt} . \% \mathrm{Al} 2 \mathrm{O} 3$ nano-composites

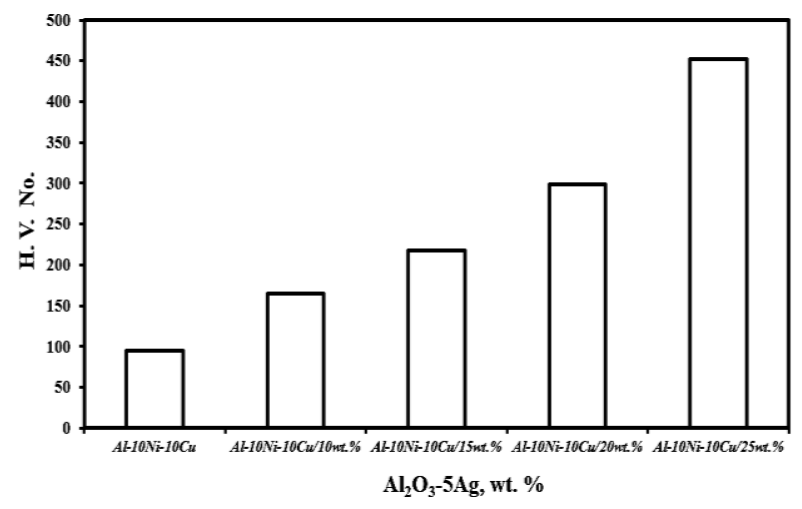

Figure 6 Micro-hardness of the fabricated nano-compoistes.

\section{Thermal Expansion}

The effect of reinforcing (Al-10Cu-10Ni) nanocomposites matrix with different percentages of $\mathrm{Al}_{2} \mathrm{O}_{3}$ and the variation of temperature on the thermal expansion coefficient is shown in figure 7. As the figure shows, the CTE increases as the temperature increases. On the other hand, the CTE decreases with increasing the $\mathrm{Al}_{2} \mathrm{O}_{3}$ content. 


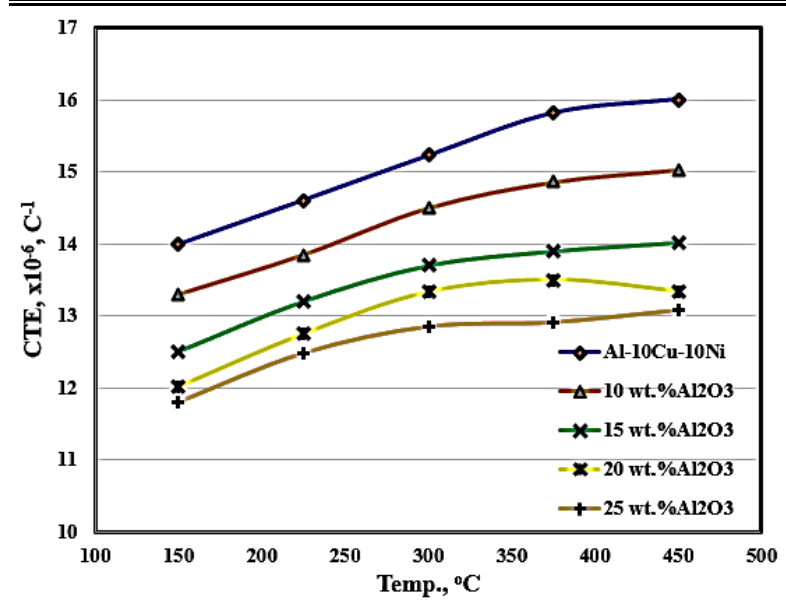

Figure 7 Coefficient of thermal expansion of the different nano-composites

\section{Conclusions}

- (Al-10Cu-10Ni)/X Al2O3 nano-composites were successfully fabricated by the hot press method.

- The hardness of the aluminium matrix nanocomposite was increased gradually with increasing the percentage of the Al2O3.

- The thermal expansion coefficient was dramatically decreased by increasing the percentage of the $\mathrm{Al} 2 \mathrm{O} 3$.

\section{References}

[1] H.M.Yehia. El-Kady, A. Abu-Oqail., Effect of diamond additions on the microstructure, physical and mechanical properties of WC- TiC- Co/Ni Nano composite, J. Refr. Meta. Hard. Mat., PP. 207-212, 2012.

[2] W. S. Barakat, O. Elkady, A. Abu-Oqail, H. M. Yehya, A. ELNikhaily, Effect of Al2O3 Coated Cu Nanoparticles on Properties of Al / Al2O3 Composites, Journal of Petroleum and Mining Engineering, (2020), 1-9

[3] H. M. Yehia, O.A. Elkady, Y. Reda, K.E. Ashraf, Electrochemical Surface Modification of Aluminium Sheets Prepared by Powder Metallurgy and Casting Techniques for Printed Circuit Applications, Transactions of the Indian Institute of Metals. Pp. 85-92, (2019).

[4] H. M. Yehia, Microstructure, physical and mechanical properties of the $\mathrm{Cu}$ / (WC-TiC-Co) nano-composites by the electro-less coating and powder metallurgy technique, Journal of Composite Materials, 11(2018) 1-9.

[5] O. El-Kady, H. M. Yehia, F. Nouh, Preparation and characterization of $\mathrm{Cu} /(\mathrm{WC}-\mathrm{TiC}-\mathrm{Co}) / \mathrm{graphene}$ nanocomposites as a suitable material for heat sink by powder metallurgy method, International Journal of Refractory Metals \& Hard Materials, 79 (2019) 108-114.
[6] H. M. Yehia, F. Nouh, O. El-Kady, Effect of graphene nanosheets content and sintering time on the microstructure, coefficient of thermal expansion, and mechanical properties of ( $\mathrm{Cu} / \mathrm{WC}-\mathrm{TiC}-\mathrm{Co}$ ) nano-composites, J. of Alloys and Compounds, 764 (2018) 36-43.

[7] S. A. Abolkassem, O. A. Elkady, A. H. Elsayed, W. A. Hussein, H. M. Yehia, Effect of consolidation techniques on the properties of $\mathrm{Al}$ matrix composite reinforced with nano Ni-coated SiC, Result in physics, 9 (2018) 1102-1111.

[8] G. Miranda, P. Ferreira, M. Buciumeanu, A. Cabral, M. Fredel, F.S. Silva, and B. Henriques "Microstructure, Mechanical and Wear Behaviors of Hot-Pressed CopperNickel-Based Materials for Diamond Cutting Tools", Journal of Materials Engineering and Performance, 26 (2017) 4046-4055.

[9] H., D. Soares, J. C.Teixeira, F.S. Silva, "Effect of Hot Pressing Variables on the Microstructure, Relative Density and Hardness of Sterling Silver (Ag-Cu alloy) Powder Compacts" Materials Research , 17 (2014) 664-671.

[10]SIMCHI and A. A. NOJOOMI, "worm compaction of metallic powders" advances in powder metallurgy, (2013) 86-201.

[11]S. Moustafa, W. Daoush1, A. Ibrahim, E. Neubauer,"Hot Forging and Hot Pressing of AISi Powder Compared to Conventional Powder Metallurgy Route" Materials Sciences and Application, 2 (2011) 1127-1133.

[12]R. C. Singh, R. Lal, M. S. Ranganath, R. Chaudhary, "Failure of piston in IC engines: A review", International Journal of Modern Engineering Research, 4 (2014) 1-10.

[13]P. Nyanor, et al Effect of Carbon Nanotube (CNT) Content on the Hardness, Wear Resistance and Thermal Expansion of In Situ Reduced Graphene Oxide ( $\mathrm{rGO}$ ) Reinforced Aluminum Matrix Composites, Metals and Materials International, Pp. 1-12, 2019.

[14]S.A. Sajjadi , H.R. Ezatpour, M. Torabi Parizi' "Comparison of microstructure and mechanical properties of A356 aluminum alloy/Al2O3 composites fabricated by stir and compo-casting processes", Materials and Design, 34 (2012)106-111

[15]Mazahery, H. Abdizadeh, H. R. Baharvandi, "Development of high-performance A356/ nano- Al2O3 composites", Materials Science and Engineering A, 518 (2009) 61-64.

[16]M. A. Elmaghraby, Hossam M. Yehia, Omayma A. Elkady, A. Abu-Oqail "Effect of Graphene Nano-Sheets Additions on the Microstructure and Wear Behavior of Copper Matrix Nano-Composite" Journal of Petroleum and Mining Engineering, Pp. 124-130, 2018.

[17]M. Rahimian, N. Ehsani, N. Parvin, H.R. Baharvandi, Journal of Materials Processing Technology 209 (2009) 5387-5393.

[18]M. Rahimian, N. Parvin, N. Ehsani, Materials Science and Engineering A: Structures 527 (2010) 1031-1038.

[19]L. Kea, Chunping Huanga, Li Xinga, Kehui Huang, "Al-Ni intermetallic composites produced in situ by friction stir processing", Journal of Alloys and Compounds, 503 (2010) 494-499. 
[20]G. Abouelmagd, "Hot deformation and wear resistance of $\mathrm{P} / \mathrm{M}$ aluminum metal matrix composites", Journal of Materials Processing Technology, 155-156 (2004) 13951401. 